\title{
The impact of metastasis on the mineral phase of vertebral bone tissue
}

\author{
Mikhail Burke, Ayelet Atkins, Alex Kiss, Margarete Akens, Albert \\ Yee, Cari Whyne
}

Version Post-print/Accepted Manuscript

Citation Burke M, Atkins A, Kiss A, Akens M, Yee A, Whyne C. The impact of (published version) metastasis on the mineral phase of vertebral bone tissue. J Mech Behav Biomed Mater. 2017 May;69:75-84. doi: 10.1016/j.jmbbm.2016.12.017

\section{Copyright/License}

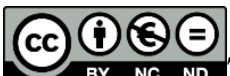

CO ${ }_{\text {BY }}$ ND This work is licensed under the Creative Commons Attribution-NonCommercial-NoDerivatives 4.0 International License. To view a copy of this license, visit Creative Commons NC BY ND 4.0 License.

How to cite TSpace items

Always cite the published version, so the author(s) will receive recognition through services that track citation counts, e.g. Scopus. If you need to cite the page number of the author manuscript from TSpace because you cannot access the published version, then cite the TSpace version in addition to the published version using the permanent URI (handle) found on the record page.

This article was made openly accessible by $U$ of $T$ Faculty. Please tell us how this access benefits you. Your story matters. 


\title{
The impact of metastasis on the mineral phase of vertebral bone tissue
}

Authors

Mikhail Burkea,b, Ayelet Atkinsb, Alex Kissc, Margarete Akensd,e, Albert Yeed,f, Cari Whynea,b,d,*

a Institution of Biomaterials and Biomedical Engineering, University of Toronto, Toronto, ON, Canada

b Orthopaedics Biomechanics Laboratory, Sunnybrook Research Institute, Toronto, ON, Canada

c Evaluative Clinical Sciences, Hurvitz Brain Science Program, Sunnybrook Research Institute, Toronto, ON, Canada

d Department of Surgery, University of Toronto, Toronto, ON, Canada

e Techna, University Health Network, Toronto, ON, Canada

f Physical Sciences, Holland Musculoskeletal Research Program, Sunnybrook Research Institute, Canada

Corresponding Author: Dr. Cari Whyne, Orthopaedics Biomechanics Laboratory, Sunnybrook Research Institute, 2075 Bayview Ave., Room S620, Toronto, ON M4N 3M5. Phone: 416-480-6100, ext. 5056.

Email: cari.whyne@sunnybrook.ca

\begin{abstract}
The negative impact of metastases on the mechanical performance of vertebral bone is often attributed to reduced bone density and/or compromised architecture. However limited characterization has been done on the impact of metastasis on the mineralization of bone tissue and resulting changes in material behaviour. This study aimed to evaluate the impact of metastasis on micro and nano scale characteristics of the mineral phase of bone, specifically mineral crystal growth, homogeneity of mineralization and changes in intrinsic material properties. Female athymic rats were inoculated with HeLa or Ace-1 cancer cells lines producing osteolytic or mixed (osteolytic \& osteoblastic) metastases respectively ( $\mathrm{N}=17$ per group). A maximum of 21 days was allowed between inoculation and sacrifice of inoculated rats and healthy age-matched uninoculated controls $(\mathrm{N}=11)$. $\mathrm{X}$-ray diffraction was used to assess average crystal size in crushed L1-L3 vertebrae; backscatter electron microscopy and nanoindentation were utilized to evaluate modifications in bone mineral density distribution and material behaviour (tissue hardness and modulus) in sagittal-sectioned, embedded and polished L5 vertebrae. HeLa inoculated samples showed reduced mineral crystal width compared to healthy controls. While both types of metastatic involvement reduced tissue mineral content, pathological osteoblastic bone, specific to Ace-1 inoculated samples, significantly decreased tissue mineral homogeneity whereas osteolytic bone from HeLa samples saw a slight increase in homogeneity. The modulus and hardness of pathological osteoblastic bone was diminished compared to all other bone. Elucidating changes in material behaviour and mineralization of bone tissue is key to defining bone quality in the presence of metastatic involvement.
\end{abstract}

Keywords: Metastasis, Vertebral Bone Quality, Mineralization, X-ray Diffraction, Backscatter Electron Microscopy, Nanoindentation 


\section{$\underline{\text { Introduction }}$}

The high incidence (33\%)\{\{80 Wong,D.A. 1990\}\} and resulting associated morbidity of metastatic involvement in the vertebral bone of cancer patients $\{\{82$ Toma,S. 1993\}\} highlights the need to elucidate the impact of tumour presence on bone tissue. While studies have established relationships between metastatic presence on the micro-architecture, bone mineral density and mechanical behaviour of vertebral bone $\{\{88$ Kaneko,T.S. 2004; 18 Wise-Milestone, Lisa 2012\}\}, only minimal attention has been given to the potential modifications to the intrinsic material characteristics of bone tissue and the resulting impact on its material behavioural properties\{\{89 Nazarian,A. 2008; 289 L.,Richert 2015\}\}.

The bone matrix is a composite material consisting of organic and mineral components whose presence, distribution and structure impact the tissue's material properties. While parallel packed collagen- I fibrils provide bone its ductility and toughness, it is the hydroxyapatite mineral phase which is responsible for providing bone with its stiffness and strength. Hydroxyapatite $(\mathrm{HA})$ is a thermodynamically stable form of calcium phosphate, whose crystal structure is hexagonal in nature $\{\{127$ Wopenka,Brigitte 2005\}\}. During bone formation, a collagen-I fibril based osteoid is produced from which associated binding matrix proteins such as bone sialoprotein facilitate the nucleation and growth of HA crystal\{\{189 Hunter,G.K. 1993\}\} within the inter and intra-fibrillar space of the collagen fibrils with the c-axis of the hexagonal crystal roughly parallel to long axis of the fibril\{\{190 Landis,W.J. 1996\}\}. The primary and secondary nucleation and growth of hydroxyapatite mineral also occurs as a time-dependant process hence there is a variability in the both the size of mineral crystals and the mineral content over time within the bone tissue microenvironment $\{\{126$ Adele Boskey 2003\}\}.

Changes in crystal dimension may alter bone's mechanical behaviour. While such changes over time in the average crystal size within bone tissue is natural; pathological bone conditions such as osteoporosis and osteogenesis imperfecta (OI) have been associated with crystal size modification \{ $\{194$ Thompson,D.D. 1983; 195 Vetter,U. 1991\}\};. Although poor bone quality and mechanical performance is associated with these conditions, the impact on bone crystal size (increased\{\{194 Thompson,D.D. 1983\}\} or decreased\{\{195 Vetter,U. 1991\}\}) is not clear and suggestions have been made as to the importance of mineral size distribution\{\{193 Fonseca, H. 2014\}\}. Metastatic involvement has been shown to decrease mineral crystallinity\{\{182 Burke,M. 2016; $130 \mathrm{Bi}, \mathrm{X} .2013\}\}$ (indicative of increased mineral carbonation and/or smaller crystal dimensions) and a feedback relationship may result as mineral crystal size can influence metastatic behaviour\{\{152 Pathi,S.P. 2011; 153 Zhu,W. 2015\}\}.

While modification in bone mineral density (BMD) has been associated with changes in mechanical behaviour and fracture risk, increased emphasis has been placed upon the impact of bone tissue quality on bone's mechanical behaviour\{\{193 Fonseca,H. 2014; 198 Friedman,A.W. 2006; 199 Seeman,Ego $2006\}$ \}. Bone mineral density distribution (BMDD) as an assessment of tissue mineralization has been suggested as a potential marker of bone quality $\{285$ Roschger,P. 2007; 239 Roschger,P. 2008\}\} as it provides information on the distribution of mineral within bone tissue (whereas BMD only highlights the average mineral content within an anatomical volume). Trabecular bone is remodelled via the formation of multiple regions (or "pockets") of focal resorption and subsequent bone creation $\{\{200$ Clarke,B. 
$2008\}$ \}. As bone tissue ages, secondary mineralization causes the amount of mineral in the tissue to increase over time; therefore older bone tissue typically has a higher mineral density than younger bone tissue $\{\{126$ Adele Boskey 2003 $\}\}$ which can impact its material behaviour $\{\{283$ Tiburtius,S. 2014; 280 Preininger,B. 2011\}\}. The time-dependence of mineral crystal nucleation and growth in conjunction with the constant remodelling of bone via osteolysis (mineral dissolution and osteoid resorption) and ossification, creates a distribution in the mineral content within bone tissue which changes over time $\{\{281$ Ruffoni,D. 2007; 282 Ruffoni,D. 2008\}\}. However, pathological conditions can potentially affect the rate and frequency of formation of these "pockets" influencing both primary and secondary mineralization, and impacting the distribution of the mineral throughout the bone structure. Bone conditions such as osteoporosis\{\{201 Roschger,P. 2001\}\}, forms of osteogenesis imperfecta $\{203$ Boyde,A. 1999\}\} and osteomalacia $\{\{202$ Roschger,P. 2003\}\} all exhibit changes in bone mineral density distribution.

Modifications within the bone tissue matrix can impact its intrinsic material properties. Several studies have utilized nanoindentation to quantitatively measure the impact of disease, potential treatments or anatomical location on bone's material properties\{\{214 Maimoun,L. 2012; 215 Hengsberger,S. 2005; 216 Ammann,P. 2007; 89 Nazarian,A. 2008\}\}. Pathological conditions have been shown to impact tissue material behaviour. In the case of osteoporosis however, while some research has shown low density bone to have significantly decreased hardness and modulus compared to controls $\{\{214$ Maimoun,L. $2012\}\}$, other studies have not found significant differences in nanoindentation parameters $\{\{286$ Guo,X.E. 2000; 287 Wang,X. 2008\}\}. Metastatic involvement has been shown to reduce the modulus and/or hardness of bone tissue compared to healthy and even osteoporotic samples\{\{89 Nazarian,A. 2008; 289 L., Richert 2015\}\}.

There is a need to elucidate both elements of bone quality and material behaviour in characterization of the impact of pathology on bone tissue. As such, this study seeks to evaluate the impact of vertebral metastatic involvement on BMDD, mineral crystal size and bone tissue stiffness and hardness. We hypothesize that the influence of metastatic disease on vertebral bone remodelling and osteogenesis will cause modifications in crystal size, mineral distribution and material behaviour properties in vertebral bone.

\section{Materials/Methods}

Animal model and metastatic inoculation

Animal use protocols, approved by the Ontario Cancer Institute, were adhered in the utilization of established models of vertebral metastases\{\{18 Wise-Milestone, Lisa 2012; 14 Engebraaten,Olav 1999; 49 Won,E. 2010\}\}. Athymic female Hsd:RHFoxn $1^{\text {rnu }}$ rats (5-6 weeks old) exhibiting pure osteolytic or mixed (osteoblastic + osteolytic) spinal lesions were produced through systemic inoculation with human HeLa cervical cancer cells (previously misidentified as MT-1 cells) or canine ACE-1 prostate cancer respectively ( $\mathrm{N}=17$ per group) via intra-cardiac injection. Both cell lines were transfected with the luciferase gene to facilitate semi-quantitative assessment of metastatic growth via bioluminescent 
imaging (IVIS Imaging system 100, Xenogen, Alameda, California) performed 14 and 21 days postinoculation. After day 21 imaging, both inoculated and healthy uninoculated age-matched control $(\mathrm{N}=11)$ athymic female rats were euthanized via $\mathrm{CO} 2$ asphyxiation, their vertebrae harvested and wrapped in saline dampened gauze, and stored in $-20^{\circ} \mathrm{C}$ freezer until testing.

\section{$\underline{\text { XRD Analysis }}$}

Methodologies such as $\mathrm{x}$-ray diffraction (XRD) facilitate absolute measurement of average crystal size dimension, helping to characterize observed changes in mineral crystallinity (via Raman Spectroscopy) $\{\{182$ Burke,M. 2016; 130 Bi,X. 2013\}\} within metastatic bone. The first to third lumbar (L1-L3) vertebrae of each rat were isolated and $\mu$ CT scanned ( $\mu$ CT 100, Scanco, Brüttisellen, Switzerland; Scan Parameters: $55 \mathrm{kVp}, 200 \mu \mathrm{A}, 11 \mathrm{~W}, 7.4 \mu \mathrm{m}$ resolution) in order to confirm tumour involvement. Visual confirmation of metastasis was demonstrated through features such as voids in the trabecular structure or abnormal bone deposits (Figure 1). After scanning, tumour burdened vertebrae were isolated and the surrounding soft tissue stripped. The vertebrae were crushed into large fragments, washed with Tris buffer saline solution and dried. Samples were placed in a 2:1 chloroform:methanol solution under agitation for a 24 hour period to facilitate sample defatting. Samples were then placed in $100 \%$ methanol solution under agitation for an hour for sample dehydration and chloroform removal, and then dried. The defatted and dried bone samples were then cryogenically impact grinded (Certiprep 6750 Freezer Mill, SPEX SamplePrep, Metuchen, New Jersey) at a rate of 20 impacts per second for 9 minutes to produce a fine bone powder $(<45 \mu \mathrm{m}$ particle size).

Bone powder samples were scanned utilizing a pXRD instrument (Philips PANalytical XRD system, Amelo, Netherlands. Consists of: PW 1830 HT generator, PW 1050 goniometer, PW3710 control electronics) similar to other studies\{\{217 Mousny,M. 2008; $240 \mathrm{Ng}$, A.H. 2016\}\}. In brief, a scan speed of $0.1^{\circ} 2 \theta / \mathrm{min}$ was utilized between diffraction angles 24 to $27^{\circ} 2 \theta$ and a scan speed of $0.05^{\circ} 2 \theta / \mathrm{min}$ was utilized between diffraction angles 37.0 to $42.0^{\circ} 2 \theta$ in order to analyze the produced $26^{\circ}$ and $40^{\circ}$ peaks associated with the (002) plane and (310) plane of the HA crystal respectively (Figure 2). The observed peak broadening $(\beta)$ was a function of the size/strain of the HA crystals in the samples and the design characteristics of the instrument. This broadening can estimated by the full-width half-maximum (FWHM) of the produced peak. The broadening contribution due to the instrument $\left(\beta_{\mathrm{i}}\right)$ was determined by scanning a silicon wafer reference at the 26 and $47^{\circ} 2 \theta$ diffraction angles and assessing the FWHM of those peaks. The corrected specimen peak broadening $\left(\beta_{1 / 2}\right)$ was equal to $\sqrt{\beta^{2}-\beta_{i}^{2}} \cdot \beta_{1 / 2}$ was then utilized within the Scherrer equation:

$$
S=\frac{180}{\pi}\left(\frac{k \lambda}{\beta_{s} \operatorname{Cos} \theta}\right) * 10^{10}
$$

where $\mathrm{K}$ is a crystal shape factor ( 0.9 for $\mathrm{HA}), \lambda$ is the $\mathrm{K}$-emission wavelength of $\mathrm{Cu}(0.154 \mathrm{~nm})$, and $\theta$ is the diffraction angle (approx. 26/2 or 40/2) in order to calculate the size of the crystal along the specific orientation of assessed parallel planes (S) in Angstroms. The (002) and (310) planes are associated with the crystal length and crystal width respectively. The FWHM of each peak was assessed using the 
Pearson VII curve fitting function of OriginPro software (OriginPro 9, OriginLab, Northampton, Massachusetts).

\section{Global cross-section BSE Analysis}

While the 2D assessment of mineral distribution can be completed via different imaging modalities, BMDD is commonly assessed via the utilization of quantitative backscatter electron microscopy (qBSE) as the intensity of image locations can be linked to calcium concentrations: a prime indicator of mineral presence. The fifth and sixth Lumbar (L5-L6) vertebrae of each rat were cut in half along the saggital plane. The specimens were dehydrated sequentially with various concentrations of acetone $(70 \%, 90 \%$, $100 \%)$. Embedding of samples in spurr epoxy resin was completed, and rough microtoming of the cured block was performed until the desired sagittal bone faces were exposed. Sample blocks were ground and polished using various grades of paper $(400,600,1200$ grit size) and diamond suspension ( $6 \mu \mathrm{m}$ and $1 \mu \mathrm{m}$ ). The sample blocks were then carbon-coated and backscatter electron (BSE) imaging was completed (SS BSE detector, FEI, Hillsboro, Oregon) using a ESEM (FEI/Philips XL30, FEI, Hillsboro, Oregon). As expanded upon elsewhere $\{233$ Roschger,P. 1998\}\}, the degree of backscatter electrons collected is a function of the atomic number of the elements in the matrix. Calcium (Ca) has higher atomic number than any other elements found in bone (e.g. carbon, nitrogen, oxygen) and is considered to be the primary contributor to BSE collected from bone tissue. Therefore, increasing brightness corresponds to increased $\mathrm{Ca}$ (hence mineral) content and as such BSE imaging can be used for mineralization profile analysis. For each sample, the BSE image intensity was calibrated to silicon dioxide and magnesium fluoride standards to determine the graylevel of pure hydroxyapatite and a standardization line built to convert BSE greylevels to wt\% Ca was built as described in previous work $\{\{233$ Roschger,P. 1998\}\}.

The entire saggital cross-section of the vertebral body was imaged at x150 nominal magnification (pixel resolution $=2 \mu \mathrm{m} /$ pixel) and histograms of the grey level distribution for the cross-section was completed. From the distribution: the full width half maximum of the peak ( $\left.\mathrm{Ca}_{\text {width }}\right)$, the peak position of the distribution $\left(\mathrm{Ca}_{\text {peak }}\right)$ and the average wt\% $\mathrm{Ca}\left(\mathrm{Ca}_{\text {mean }}\right)$ were assessed utilizing custom Microsoft Excel script. These characteristics are indicative of the heterogeneity of mineral distribution, shift in the mineral distribution and average mineral content respectively.

Observable characteristics of tumour burden on bone morphology such as voids in trabecular structure (i.e. osteolytic involvement) and atypical "feathery/lacy/lattice" bone morphology (i.e. osteoblastic involvement), which have been observed in histological work in previous studies $\{\{18$ Wise-Milestone, Lisa 2012; 49 Won,E. 2010\}\}, were identified within these images to qualitatively determine metastatic presence and general location (Figure 3 ).

\section{Nanoindentation and Location Specific BSE Analysis}

Mechanically relevant material characteristics of bone tissue (e.g. elastic modulus and hardness) can be assessed via nanoindentation. For $\mathrm{N}=15$ of the same blocks prepared for global BSE analysis (HeLa: $\mathrm{N}=5$, Ace-1: $N=5$, Healthy: $N=5)$, the blocks were further polished with diamond suspension ( $6 \mu \mathrm{m}, 1 \mu \mathrm{m}, 0.25$ $\mu \mathrm{m}$ and $0.05 \mu \mathrm{m}$ ) to facilitate removal of the carbon coating and additional smoothing of the bone 
surface. The intrinsic mechano-material properties of the bone were determined via nanoindentation (UNHT, Anton Parr, Graz, Austria). The utilization of the Oliver-Pharr method in the determination of bone material properties has been well documented and applied in other studies $\{234$ Lewis,G. 2008; 214 Maimoun,L. 2012; 215 Hengsberger,S. 2005\}\}. Within this study, the Berkovich indenter tip was used to apply a load ( $4000 \mu \mathrm{N}$ maximum) at a rate of $400 \mu \mathrm{N} / \mathrm{s}$ onto the bone surface. This load was held for 10 seconds and then unloaded at the same rate. The hardness $(\mathrm{H})$ of the tissue is a function of the maximum load and the produced contact area of tip to the surface. The elastic modulus $(E)$ of the bone is function of the gradient of the unloading curve. These parameters describe bone's plastic and elastic deformation properties, respectively.

Nanoindentation testing has been done with either the specimen dry or wet, however with a $10-40 \%$ difference in measured hardness and modulus values between the two conditions $\{\{212$ Guidoni,G. 2010; 213 Dall'Ara,E. 2007\}\}. To establish wet testing conditions, sample blocks were submerged in saline solution for 90 minutes prior to and during testing. To determine the impact of tumour presence on these properties, regions of interest (ROI) were chosen adjacent to tumour and included trabecular bone near the edge of the trabecular centrum which had not completed endochrondral ossification (therefore a more nascent tissue mixture of lamellar bone, woven bone and cartilage (Edge)), more mature fully lamellar trabecular bone situated closer to the middle of the trabecular centrum (Centre), as well as both anterior (CortA) and posterior (CortP) walls of the cortical shell. Additionally, observed pathological new bone formation resulting from osteoblastic lesions (New) specific to Ace-1 samples were analyzed and all data sets were compared to healthy controls. Selection of ROI was based on the same bone morphological cues as described with the global BSE images and was facilitated by the use of an attached light microscope (LM). Note, due to the focal nature of vertebral lesions, it was possible that not every relevant ROI group existed for a particular sample. Testing for each identified ROI consisted of 4 indent points in a square formation which were 10-20 $\mu \mathrm{m}$ apart from one another. Data points from indents within 3 indent lengths of the epoxy/bone interface were removed before analysis.

After nanoindentation, the blocks were reimaged with BSE microscopy (to account for likely changes in observed cross-section after further polishing for nanoindentation). The LM images obtained for each ROI selected for nanoindentation analysis were superimposed over the corresponding area in these newly attained BSE images and a 100×100 pixel area (with the 4 indent points defining the centre of the ROI) was chosen (Figure 4). Grey-level distribution analysis was performed in this defined area in order to assess potential differences in localized mineralization profiles within specific regions of the vertebral body that were tested via nanoindentation. Furthermore, $2 \times 2$ pixel areas were chosen by the approximate site of each indentation area in order to assess the average $\mathrm{wt} \% \mathrm{Ca}$ adjacentthe indent location ( $\mathrm{Ca}_{\text {ind }}$ )for further localization of the impact of mineralization on bone's material properties.

\section{Statistical Analysis}

For XRD and whole cross-sectional BSE analysis, Welsh followed by Tamhane post hoc tests for multiple comparisons were performed to test for differences between sample groups without equal variance. In cases with equal variance and normality, analysis of variance (ANOVA) followed by Tukey post hoc test was used. For nanoindentation and locational BSE analysis, multiple-way ANOVAs were performed 
based on a parametric mixed model approach utilized in similarly structured test designs $\{\{214$ Maimoun,L. 2012; 215 Hengsberger,S. 2005\}\}. The factors "metastatic involvement" (HeLa, Ace-1 and Healthy) and "location" (Centre, Edge, CortA, CortP and New) were set to fixed effects. "Sample" (5 rats per metastatic involvement group) was considered a random factor; allowing the model to account for repeated unaveraged measurements within a sample. As no statistically significant interaction effect was seen between metastatic involvement and location (factor: location*metastatic involvement, $p>0.05)$, tukey's post hoc test was used for multiple comparisons between groups. For testing the relationship between $\mathrm{E}$ or $\mathrm{H}$ with either $\mathrm{Ca}_{\text {mean }}$ or $\mathrm{Ca}_{\text {Ind }}$, Pearson rank order correlations were used. In all cases, data was presented as mean \pm standard deviation-, with a significance level of $p<0.05$ (SPSS v23, SPSS, Chicago, Illinois,).

\section{$\underline{\text { Results }}$}

\section{Metastatic Involvement:}

Bioluminescent imaging showed metastatic tumour growth in the spine was found in 14/17 rats injected with HeLa cells and 12/17 rats injected with Ace-1 cells. Additional tumour signal appeared in the heart, lungs and femurs. A total of 24 rat L1-L3 vertebrae samples (HeLa: $\mathrm{N}=9$; Ace-1: $\mathrm{N}=7$; Healthy: $\mathrm{N}=8$ ) were $\mu C T$ scanned, had established tumour presence (where applicable) and analyzed via XRD. A total of 25 rat L5-L6 vertebrae (HeLa: $\mathrm{N}=9$; Ace-1: $\mathrm{N}=5$; Healthy: $\mathrm{N}=11$ ) were BSE imaged, had established tumour presence (where applicable) and had further grey-level distribution analysis completed. For nanoindentation and location specific BSE analysis, a total of 15 rat vertebrae (HeLa: $\mathrm{N}=5$; Ace-1: $\mathrm{N}=5$; Healthy: $N=5$ ) were assessed.

XRD:

Purely osteolytic bone (via HeLa inoculation) displayed a significant decrease (18.1\%) in HA crystal width compared to healthy controls. Mixed bone (via Ace-1 inoculation) showed no statistical difference to control in HA crystal width and there was no significant difference in HA crystal length among any of the sample groups (Table 1).

\section{BSE (Global Cross-Section):}

The mineral distribution profile throughout the vertebral body changed with mixed metastatic involvement (Figure 5a). The vertebral cross-section of mixed metastatic bone showed a significant increase $(>60 \%)$ in the $\mathrm{Ca}_{\text {width }}$ and a decrease $(>9.5 \%)$ in the $\mathrm{Ca}_{\text {mean }}$ compared to both osteolytic bone and healthy controls (Figure 5b). Although Capeak for mixed bone was also lower compared to healthy controls, this difference was not significant. There was no observable difference between osteolytic bone and healthy controls for any of the characteristics measured at this scope.

\section{BSE (Location Based):}

Multiple-way ANOVA showed that both type and location had a significant impact on both the $\mathrm{Ca}_{\text {width }}$ and $\mathrm{Ca}_{\text {mean }}$ and that only location had a significant impact on $\mathrm{Ca}_{\text {peak. }}$. Bone from the Ace-1 inoculated rats showed a wider $\mathrm{Ca}_{\text {width }}$ ( $41 \%$ increase, i.e. greater heterogeneity of mineral distribution) compared to 
healthy controls. Conversely, bone from HeLa inoculated rats showed a thinner Ca width ( $19 \%$ decrease, i.e. more homogeneous mineral distribution, $p<0.05$ ) compared to the healthy controls (Figure 6a). Pathological new bone growth particular to Ace-1 inoculated samples showed a much greater $\mathrm{Ca}_{\text {width }}$ (ranging from $53 \%$ to $139 \%$ increases, $p<0.01$ ) compared to bone in any other location of the vertebral body (Figure 6b). The anterior cortical wall (CortA) as exhibited a larger $\mathrm{Ca}_{\text {width }}$ than Centre and CortP regions $(50-56 \%$ increase, $p<0.05)$.

Bone from the Ace-1 inoculated rats showed a significant decrease $(>13 \%, p<0.05)$ in $\mathrm{Ca}_{\text {mean }}$ (average mineral content) compared to bone from both healthy and HeLa inoculated samples. Bone from HeLa inoculated samples showed a small decrease $(\sim 4.5 \%, \mathrm{p}<0.05)$ in $\mathrm{Ca}_{\text {mean }}$ compared to healthy controls (Figure 7a). Pathological new bone growth showed a much smaller $\mathrm{Ca}_{\text {mean }}$ (ranging from $15 \%$ to $21 \%$ decrease, $p<0.01$ ) compared to bone in any other location of the vertebral body (Figure $7 \mathrm{~b}$ ). The posterior cortical wall (CortP) showed a slightly smaller $\mathrm{Ca}_{\text {mean }}$ compared to the centre region.

Although there was no difference between type for $\mathrm{Ca}_{\text {peak, }}$, the pathological osteoblastic bone growth seen in Ace-1 inoculated samples, showed a significant decrease in $\mathrm{Ca}_{\text {peak }}$ compared to bone in any other region (Figure $8 \mathrm{a} / \mathrm{b}$ ).

\section{Nanoindentation:}

Multiple-way ANOVA showed no significant difference in the modulus $(E)$ and hardness $(H)$ of bone tissue globally (i.e. independent of location) between metastatic involvement groups. However, location was determined to be a significant factor. In particular, pathological osteoblastic bone growth, specific to Ace-1 tumour involvement, generally showed lower $\mathrm{E}$ and $\mathrm{H}$ values compared to other locations (Figure 9). This implies that the impact of tumour involvement on material behaviour is focused towards pathological new bone locations. Additionally, trabecular bone at Edge showed a slightly higher $\mathrm{E}$ and $\mathrm{H}$ than bone locations such as the Centre and CortP. A weak correlation was shown between $E(R=0.243$, $p<0.01)$ and $H(R=0.228, p<0.01)$ with $C_{\text {Ind. }}$. Specifically within pathological osteoblastic bone, where differences in material behaviour were significant, the regional $\mathrm{Ca}_{\text {mean }}$ showed correlation with both material properties ( $E: R=0.521, p<0.05 ; H: R=0.484, p<0.05$ ).

Summary of all location based data from each sample group can be found in supplementary material..

\section{Discussion}

Bone mineral crystal dimension, the intrinsic mineral content of bone tissue and the distribution of mineral throughout bone structure were all found to exhibit changes due to metastatic involvement. The impact of tumour presence on bone mineral goes deeper than the commonly analyzed bone mineral density (BMD) and can be found at both micro and nano levels. With normal bone remodelling, characteristics defined by BMDD (i.e heterogeneity of mineral distribution) are influenced by the primary and secondary mineralization of newer bone (mediated by osteoblasts) and the resorption of older bone (osteoclast mediated) as well as rate and number of these bone remodelling pockets $\{\{239$ Roschger,P. 2008\}\}. Such bone remodelling is mediated by a number of cytokines such as PTHrP and IL-6 
which impact osteoclastic function or TGF- $\beta$ which impacts osteoblastic function. Metastatic involvement can modify the level of these cytokines in the bone microenvironment impacting natural bone remodelling $\{269$ Guise,T. 2010\}\}. This is highlighted in the study results by the observed modification in homogeneity of mineral distribution at the whole vertebral body level with metastatic involvement. Bone within the Ace-1 inoculated samples showed much greater heterogeneity of mineral distribution (greater $\mathrm{Ca}_{\text {width }}$ ) compared to both HeLa inoculated and healthy controls. This heterogeneity can be attributed to growth of less mineralized pathological new bone existing with older osteolytic bone in the presence of mixed metastases. Additionally, the observed increase in mineral distribution heterogeneity of isolated regions of pathological new bone formation is similar to bone observed in pathological conditions such as osteomalacia and osteoporosis\{\{202 Roschger,P. 2003; 201 Roschger,P. $2001\}\}$. In contrast however, bone from HeLa inoculated samples showed a slight increase in homogeneity in mineral distribution (smaller $\mathrm{Ca}_{\text {width }}$ ) compared to controls. It has been previously speculated that increases in localized mineral homogeneity could lead to increased bone brittleness and fracture risk\{\{237 Boskey,A.L. 2009; 238 Renders,G.A.P. 2011\}\}, which could be a contributing factor in previously observed weakening of vertebrae with HeLa induced metastatic involvement \{\{49 Won,E. $2010\}$ \}. This contrast suggests that there is an optimal mineral distribution range for bone to indicate both a healthy mineralization profile and mechanical performance. Such characterization of mineral distribution homogeneity builds upon average mineral content reported by previous BSE analysis of metastatic bone samples $\{\{89$ Nazarian,A. 2008\}\}. Also, while the anterior cortical wall bone (CortA) also showed a larger $\mathrm{Ca}_{\text {width }}$ than some areas (e.g. Centre, CortP), this is could be attributed to the new bone growth being within the ROI as such growth shows a propensity to grow on the anterior cortical wall.

The lower average mineral content (smaller $\mathrm{Ca}_{\text {mean }}$ ) also observed in metastatically involved bone could be due to a number of potential causes. Tumour presence and intensified osteolytic action is linked to a decrease in the $\mathrm{pH}$ of the bone microenvironment $\{\{133$ Yoneda,T. 2011 $\}\}$ which can impact the functionality of alkaline phosophate, a pH sensitive enzyme whose function is to provide inorganic phosphate (via pyrophosphate hydrolysis) for mineralization\{\{223 Brandao-Burch,A. 2005\}\}. Also, the HA mineral exhibits increased solubility at a lower $\mathrm{pH}$ which would lower mineral content $\{2224$ Mahapatra,P.P. 1982\}\}. Such observations are in line with reduced average mineral content seen with metastatic involvement in human samples $\{\{89$ Nazarian,A. 2008\}\}. While these mechanisms could explain the decrease in mineral content in the pure osteolytic (HeLa inoculated) model, the timedependant nature of mineralization $\{\{282$ Ruffoni,D. 2008\}\} could also be a major contributing factor to the much lower $\mathrm{Ca}_{\text {mean }}$ observed in the mixed metastatic (Ace-1 inoculated) model which contained significant amounts of new pathological bone growth ( $<21$ days old). This could also explain the shift in the mineralization profile of osteoblastic bone growth towards lower mineralization values (lower $\left(a_{\text {peak }}\right)$.

Previous work had alluded to a potential decrease in metastatic bone mineral crystal size via a decrease in observed crystallinity with Raman spectroscopy\{\{182 Burke,M. 2016; $130 \mathrm{Bi}, \mathrm{X} .2013\}\}$. The present work corroborated this finding with the observed decreases in the mineral crystal width with metastatic involvement, in particular within the osteolytic bone model (HeLa). Factors such as bone sialoprotein, which are associated with nucleation of tissue mineral, have also been shown to be expressed in tumour 
associated with bone metastasis $\{222 \mathrm{lbrahim}, \mathrm{T} .2000\}\}$. An increase in bone sialoprotein could lead to more mineral nucleation sites that may increase the number of mineral crystals and lower the size of these crystals due to spatial and ion constraints. Decreased HA crystal size has also been associated with promoting tumour metastases $\{152$ Pathi,S.P. 2011\}\} further supporting that metastasis/mineral interaction may be cyclic in nature. Although modifications in bone crystal size could be linked to diminished mechanical performance, opposing correlations have suggested greater importance on the distribution of crystal size\{\{126 Adele Boskey 2003\}\}. While no significant difference in bone crystal size was observed in Ace-1 inoculated specimens, future work is required to evaluate potential differences in mineral size distribution.

Modifications in the intrinsic material behaviour of bone tissue was observed within pathological osteoblastic bone growth. The decrease in both the modulus and hardness of this particular bone compared to bone tissue elsewhere in the vertebral body shows that tumour-induced osteoblastic bone growth not only has modified morphology which could impact its functionality macroscopically, but is indicative of changes in tissue level properties as well. Reduced material behaviour has been demonstrated with metastatic involvement in human vertebral bone using BSE and nanoindentation techniques, however such analyses have not distinguished between the osteoblastic/osteolytic nature of the samples, nor were locational effects, proximity to the tumour tissue or previous treatments that may have affected the samples (i.e. bisphosphonates, radiation, etc...) described\{\{89 Nazarian,A. 2008\}\}. Other metastatic bone models have suggested reduced bone tissue modulus with breast cancer involvement (described as osteolytic), however proximity to lesions, location and indentation of potential osteoblastic growth (as may be inferred in the published radiographs) were not considered in the analysis\{\{289 L.,Richert 2015\}\}.

The described modification in mineralization profile and lower average mineral content of osteoblastic bone could be a contributing factor to the decreased bone hardness and modulus. The reduced fraction of the stiffer and harder HA crystal within the bone tissue matrix would decrease the assessed material properties of the organic composite. Other work has previously observed correlation between average mineral content and both bone hardness and modulus\{\{235 Fratzl-Zelman,N. 2009\}\} and similar correlations were established in this study between $\mathrm{Ca}_{\text {mean }}$ or $\mathrm{Ca}_{\text {ind }}$ and these nano-indentation parameters. Although the Edge location data showed a larger $\mathrm{E}$ or $\mathrm{M}$ than some other locations (e.g. Centre, CortP), this could be attributed to the presence of highly mineralized cartilage during the early stages of endochrondral ossification.

While similar trends in mineralization and material behaviour could potentially be associated with the nascent nature of osteoblastic bone as compared to its diseased state, differences between this pathological new bone and healthy newly formed bone can exist. For example, previous work has shown that this new osteoblastic bone growth has a woven-like bone osteoid that is usually associated with early stages of endochrondral ossification or fracture healing $\{265$ Burke,M. $\}\}$. However, this new osteoblastic bone was found to have a decrease in the concentration of canaliculi compared to healthy woven bone $\{265$ Burke,M. $\}\}$ which in turn could impact mineralization and bone formation $\{\{267$ Kobayashi,Keiji 2015\}\}. This suggests that material level differences in tumour-induced osteoblastic bone do exist and the combination of modified mineralization observed in this study with previously observed 
changes in fibril organization and potential modifications in collagen-cross-linking with metastatic involvement $\{\{182$ Burke,M. 2016\}\} could explain the differences in material behaviour. It is possible that the combination of the diseased nature of the osteoblastic bone with the increased volume of new bone together contribute to diminished mechanical behaviour associated with mixed metastasis. Future work characterizing age-matched new bone formation (i.e. through sequential in vivo staining) may isolate the impact of the pathologic characteristics of osteoblastic bone on material and mechanical behaviour.

Although the results highlight that the presence of metastatic disease impacts both the mineralization profile and material behaviour of vertebral bone, some limitations with respect to utilized methodologies must be noted. First, the embedding process and the type of embedding material used for nanoindentation could potentially impact recorded results for the absolute values for measured material properties\{\{236 Mittra,E. 2006\}\} due to infiltration into the tissue matrix. Although not ideal, embedding is necessary to provide support for the small rat trabeculae during loading. Despite this, all samples went through identical embedding and preparation protocols, yielding relevant measured differences. The utilized cell lines chosen for the study were selected based on their previously established ability to create vertebral metastases. Previous work has shown no difference in metastatic response to Ace-1 cells between male and female rats\{\{18 Wise-Milestone, Lisa 2012 $\}$. For consistency, both HeLa and Ace-1 cells were injected into female rats. The animal and tissue origins of the utilized tumour cell lines for osteoblastic and mixed metastatic production differed, however, the immune compromised nature of the rats should minimize any impact of cell species differences in the context of this study. Finally, while the signal-to-noise ratio of some produced peaks in the XRD analysis was not ideal (due to presence of organic material), temperatures required to burn off organic material could impact crystal size/structure and hence were avoided.

\section{Conclusion}

This study showed that crystal width, tissue mineral content and mineral distribution within rat vertebral bone are all altered under metastatic involvement and that in particular the material behaviour of tumour-induced osteoblastic bone is negatively impacted by such changes. Future work will need to establish the potential impact of such material level changes on the mechanical behaviour of vertebrae to better understand and model the impact of metastatic involvement on the mechanical integrity of the spine with the end goal of identifying target areas for future and current treatment options.

\section{Acknowledgements}

Grant funding for this study was provided by the Canadian Institutes of Health Research (\#68911 and $\# 125886)$. The authors declare that there are no conflicts of interest. 


\section{$\underline{\text { References }}$}

Adele, Boskey, 2003. Bone mineral crystal size. Osteoporos. Int. 14 (Suppl 5), S20-S21. Ammann, P., Badoud, I., Barraud, S., Dayer, R., Rizzoli, R., 2007. Strontium ranelate treatment improves trabecular and cortical intrinsic bone tissue quality, a determinant of bone strength. J. Bone Miner. Res. 22, 1419-1425.

Bi, X., Sterling, J.A., Merkel, A.R., Perrien, D.S., Nyman, J.S., Mahadevan-Jansen, A., 2013. Prostate cancer metastases alter bone mineral and matrix composition independent of effects on bone architecture in mice - a quantitative study using microCT and raman spectroscopy. Bone 56, 454-460.

Boskey, A.L., Spevak, L., Weinstein, R.S., 2009. Spectroscopic markers of bone quality in alendronate-treated postmenopausal women. Osteoporos. Int. 20, 793-800.

Boyde, A., Travers, R., Glorieux, F.H., Jones, S.J., 1999. The mineralization density of iliac crest bone from children with osteogenesis imperfecta. Calcif. Tissue Int. 64, 185-190.

Brandao-Burch, A., Utting, J.C., Orriss, I.R., Arnett, T.R., 2005. Acidosis inhibits bone formation by osteoblasts in vitro by preventing mineralization. Calcif. Tissue Int. 77, 167-174.

M. Burke, A.Golaraei, A.Atkins, M.Akens, V.Barzda, C.Whyne, 2016a. Collagen fibril organization within rat vertebral bone modified with metastatic involvement, J. Struct. Biol. (Submitted for publication).

Burke, M., Atkins, A., Akens, M., Willett, T., Whyne, C., 2016b. Osteolytic and mixed cancer metastasis modulates collagen and mineral parameters within rat vertebral bone matrix. J. Orthop. Res..

Clarke, B., 2008. Normal bone anatomy and physiology. Clin. J. Am. Soc. Nephrol. 3 (Suppl 3), S131-S139.

Dall'Ara, E., Ohman, C., Baleani, M., Viceconti, M., 2007. The effect of tissue condition and applied load on vickers hardness of human trabecular bone. J. Biomech. 40, 3267-3270.

Engebraaten, O., Fodstad, $\varnothing$., 1999. Site-specific experimental metastasis patterns of two human breast cancer cell lines in nude rats. Int. J. Cancer. 82, 219-225.

Fonseca, H., Moreira-Goncalves, D., Coriolano, H.J., Duarte, J.A., 2014. Bone quality: the determinants of bone strength and fragility. Sport. Med. 44, 37-53.

Fratzl-Zelman, N., Roschger, P., Gourrier, A., Weber, M., Misof, B.M., Loveridge, N., Reeve, J., Klaushofer, K., Fratzl, P., 2009. Combination of nanoindentation and quantitative backscattered electron imaging revealed altered bone material properties associated with femoral neck fragility. Calcif. Tissue Int. 85, 335-343. Friedman, A.W., 2006. Important determinants of bone strength: beyond bone mineral density. J. Clin. Rheumatol. 12, 70-77.

Guidoni, G., Swain, M., JÃ ager, I., 2010. Nanoindentation of wet and dry compact bone: influence of environment and indenter tip geometry on the indentation modulus.

Philos. Mag. 90, 553-565. 
Guise, T., 2010. Examining the metastatic niche: targeting the microenvironment. Semin. Oncol. 37 (Suppl 2), S2-14.

Guo, X.E., Goldstein, S.A., 2000. Vertebral trabecular bone microscopic tissue elastic modulus and hardness do not change in ovariectomized rats. J. Orthop. Res. 18, 333-336.

Hengsberger, S., Ammann, P., Legros, B., Rizzoli, R., Zysset, P., 2005. Intrinsic bone tissue properties in adult rat vertebrae: modulation by dietary protein. Bone 36 , 134-141.

Hunter, G.K., Goldberg, H.A., 1993. Nucleation of hydroxyapatite by bone sialoprotein. Proc. Natl. Acad. Sci. USA 90, 8562-8565.

Ibrahim, T., Leong, I., Sanchez-Sweatman, O., Khokha, R., Sodek, J., Tenenbaum, H.C., Ganss, B., Cheifetz, S., 2000. Expression of bone sialoprotein and osteopontin in breast cancer bone metastases. Clin. Exp. Metastas-. 18, 253-260.

Kaneko, T.S., Bell, J.S., Pejcic, M.R., Tehranzadeh, J., Keyak, J.H., 2004. Mechanical properties, density and quantitative $\mathrm{CT}$ scan data of trabecular bone with and without metastases. J. Biomech. 37, 523-530.

Kobayashi, K., Nojiri, H., Saita, Y., Morikawa, D., Ozawa, Y., Watanabe, K., Koike, M., Asou, Y., Shirasawa, T., Yokote, K., Kaneko, K., Shimizu, T., 2015. Mitochondrial superoxide in osteocytes perturbs canalicular networks in the setting of age-related osteoporosis. Sci. Rep. 5, 9148.

Landis, W.J., 1996. Mineral characterization in calcifying tissues: atomic, molecular and macromolecular perspectives. Connect. Tissue Res. 34, 239-246.

Lewis, G., Nyman, J.S., 2008. The use of nanoindentation for characterizing the properties of mineralized hard tissues: state-of-the art review. J. Biomed. Mater. Res. B. Appl. Biomater. 87, 286-301.

Mahapatra, P.P., Mishra, H., Chickerur, N.S., 1982. Solubility of hydroxyapatite and related thermodynamic data. Thermochim. Acta. 52, 333-336.

Maimoun, L., Brennan-Speranza, T.C., Rizzoli, R., Ammann, P., 2012. Effects of ovariectomy on the changes in microarchitecture and material level properties in response to hind leg disuse in female rats. Bone 51, 586-591.

Mittra, E., Akella, S., Qin, Y.X., 2006. The effects of embedding material, loading rate and magnitude, and penetration depth in nanoindentation of trabecular bone. J. Biomed.

Mater. Res. A 79, 86-93.

Mousny, M., Omelon, S., Wise, L., Everett, E.T., Dumitriu, M., Holmyard, D.P., Banse, X., Devogelaer, J.P., Grynpas, M.D., 2008. Fluoride effects on bone formation and mineralization are influenced by genetics. Bone. 43, 1067-1074.

Nazarian, A., von Stechow, D., Zurakowski, D., Muller, R., Snyder, B.D., 2008. Bone volume fraction explains the variation in strength and stiffness of cancellous bone affected by metastatic cancer and osteoporosis. Calcif. Tissue Int. 83, 368-379. Ng, A.H., Omelon, S., Variola, F., Allo, B., Willett, T.L., Alman, B.A., Grynpas, M.D., 2016. Adynamic bone decreases bone toughness during aging by affecting mineral and matrix. J. Bone Miner. Res. 31, 369-379. 
Pathi, S.P., Lin, D.D.W., Dorvee, J.R., Estroff, L.A., Fischbach, C., 2011. Hydroxyapatite nanoparticle-containing scaffolds for the study of breast cancer bone metastasis.

Biomaterials. 32, 5112-5122.

Preininger, B., Checa, S., Molnar, F.L., Fratzl, P., Duda, G.N., Raum, K., 2011. Spatialtemporal mapping of bone structural and elastic properties in a sheep model following osteotomy. Ultrasound Med. Biol. 37, 474-483.

Renders, G.A.P., Mulder, L., van Ruijven, L.J., Langenbach, G.E.J., van Eijden, T.M.G.J., 2011. Mineral heterogeneity affects predictions of intratrabecular stress and strain.

J. Biomech. 44, 402-407.

Richert, L., Keller, L., Wagner, Q., Bornert, F., Gros, C., Bahi, S., Clauss, F., Bacon, W., Clezardin, P., Benkirane-Jessel, N., Fioretti, F., 2015. Nanoscale stiffness

distribution in bone metastasis. World J. Nano Sci. Eng. 5, 219-228.

Roschger, P., Fratzl, P., Eschberger, J., Klaushofer, K., 1998. Validation of quantitative backscattered electron imaging for the measurement of mineral density distribution in human bone biopsies. Bone. 23, 319-326.

Roschger, P., Rinnerthaler, S., Yates, J., Rodan, G.A., Fratzl, P., Klaushofer, K., 2001. Alendronate increases degree and uniformity of mineralization in cancellous bone and decreases the porosity in cortical bone of osteoporotic women. Bone 29, 185-191.

Roschger, P., Gupta, H.S., Berzlanovich, A., Ittner, G., Dempster, D.W., Fratzl, P., Cosman, F., Parisien, M., Lindsay, R., Nieves, J.W., Klaushofer, K., 2003. Constant mineralization density distribution in cancellous human bone. Bone 32, 316-323. Roschger, P., Dempster, D.W., Zhou, H., Paschalis, E.P., Silverberg, S.J., Shane, E., Bilezikian, J.P., Klaushofer, K., 2007. New observations on bone quality in mild primary hyperparathyroidism as determined by quantitative backscattered electron imaging. J. Bone Miner. Res. 22, 717-723.

Roschger, P., Paschalis, E.P., Fratzl, P., Klaushofer, K., 2008. Bone mineralization density distribution in health and disease. Bone. 42, 456-466.

Ruffoni, D., Fratzl, P., Roschger, P., Klaushofer, K., Weinkamer, R., 2007. The bone mineralization density distribution as a fingerprint of the mineralization process. Bone. 40, 1308-1319.

Ruffoni, D., Fratzl, P., Roschger, P., Phipps, R., Klaushofer, K., Weinkamer, R., 2008. Effect of temporal changes in bone turnover on the bone mineralization density distribution: a computer simulation study. J. Bone Miner. Res. 23, 1905-1914. Seeman, E., Delmas, P.D., 2006. Bone quality â $€$ " the material and structural basis of bone strength and fragility. N. Engl. J. Med. 354, 2250-2261.

Thompson, D.D., Posner, A.S., Laughlin, W.S., Blumenthal, N.C., 1983. Comparison of bone apatite in osteoporotic and normal eskimos. Calcif. Tissue Int. 35, 392-393.

Tiburtius, S., Schrof, S., Molnar, F., Varga, P., Peyrin, F., Grimal, Q., Raum, K., Gerisch, A., 2014. On the elastic properties of mineralized turkey leg tendon tissue: multiscale model and experiment. Biomech. Model. Mechanobiol. 13, 1003-1023. Toma, S., Venturino, A., Sogno, G., Formica, C., Bignotti, B., Bonassi, S., Palumbo, R., 
1993. Metastatic bone tumors. nonsurgical treatment. outcome and survival. Clin. Orthop. Relat. Res. 295, 246-251.

Vetter, U., Eanes, E.D., Kopp, J.B., Termine, J.D., Robey, P.G., 1991. Changes in apatite crystal size in bones of patients with osteogenesis imperfecta. Calcif. Tissue Int. 49, 248-250.

Wang, X., Sudhaker Rao, D., Ajdelsztajn, L., Ciarelli, T.E., Lavernia, E.J., Fyhrie, D.P., 2008. Human iliac crest cancellous bone elastic modulus and hardness differ with bone formation rate per bone surface but not by existence of prevalent vertebral fracture. J. Biomed. Mater. Res. B. Appl. Biomater. 85, 68-77.

Wise-Milestone, L., Akens, M.K., Rosol, T.J., Hojjat, S., Grynpas, M.D., Whyne, C.M., 2012. Evaluating the effects of mixed osteolytic/osteoblastic metastasis on vertebral bone quality in a new rat model. J. Orthop. Res. 30, 817-823.

Won, E., Wise-Milestone, L., Akens, M.K., Burch, S., Yee, A.J., Wilson, B.C., Whyne, C.M., 2010. Beyond bisphosphonates: photodynamic therapy structurally augments metastatically involved vertebrae and destroys tumor tissue. Breast Cancer Res.

Treat. 124, 111-119.

Wong, D.A., Fornasier, V.L., MacNab, I., 1990. Spinal metastases: the obvious, the occult, and the impostors. Spine 15, 1-4, (Phila. Pa. 1976).

Wopenka, B., Pasteris, J.D., 2005. A mineralogical perspective on the apatite in bone. Mater. Sci. Eng.: C; NATO Adv. Study Inst. (ASI Learn. Nat. How Des. New Implant. Biomater.: Biominer. Fundam. Biomim. Mater. Process. Routes) NATO Adv. Study I(TRUNCATED) 25, 131-143.

Yoneda, T., Hata, K., Nakanishi, M., Nagae, M., Nagayama, T., Wakabayashi, H., Nishisho, T., Sakurai, T., Hiraga, T., 2011. Involvement of acidic microenvironment in the pathophysiology of cancer-associated bone pain. Bone. 48, 100-105.

Zhu, W., Wang, M., Fu, Y., Castro, N.J., Fu, S.W., Zhang, L.G., 2015. Engineering a biomimetic three-dimensional nanostructured bone model for breast cancer bone metastasis study. Acta Biomater. 14, 164-174.

M. Burke et al. Journal of the mechanical behavior of biomedical materials 69 (2017) 75-84 84 


\section{Figure 1}
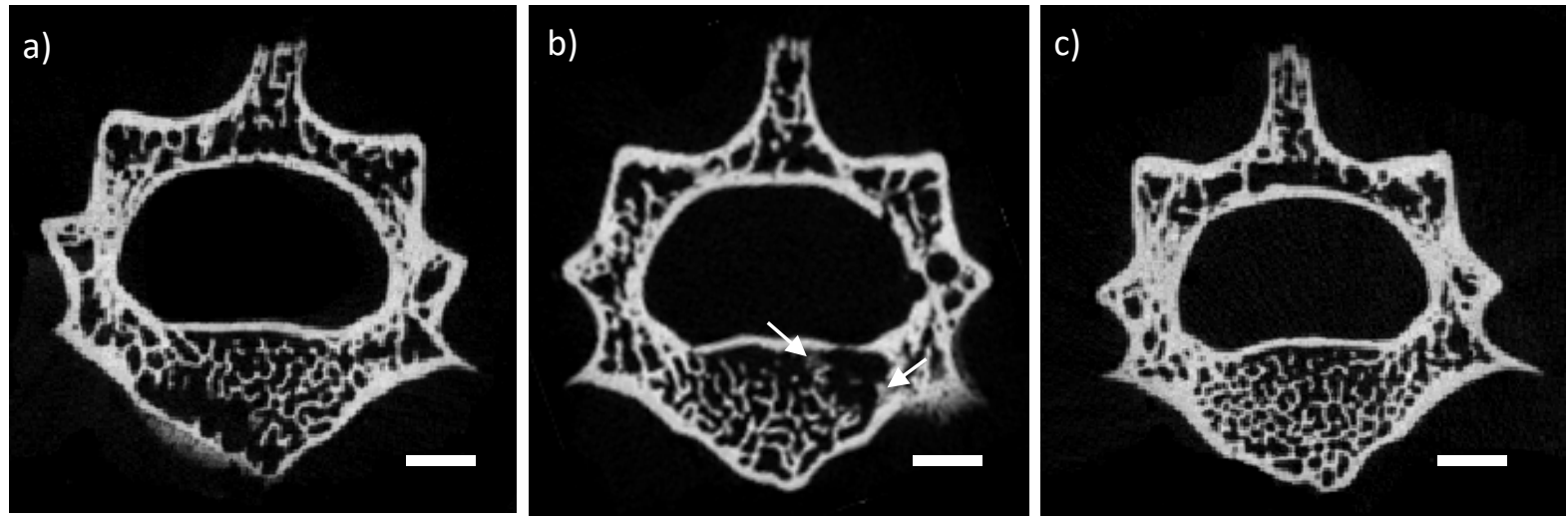

Figure 1: Representative axial cross-section uCT images of scanned vertebrae for a) HeLa inoculated b) Ace-1 inoculated and c) healthy control rats. Tumour presence in a) and b) is clearly identifiable with voids in trabecular structure with metastatic involvement. Osteoblastic bone growth (highlighted via arrow) observable in b). Scale bar $=1 \mathrm{~mm}$. 


\section{Figure 2}
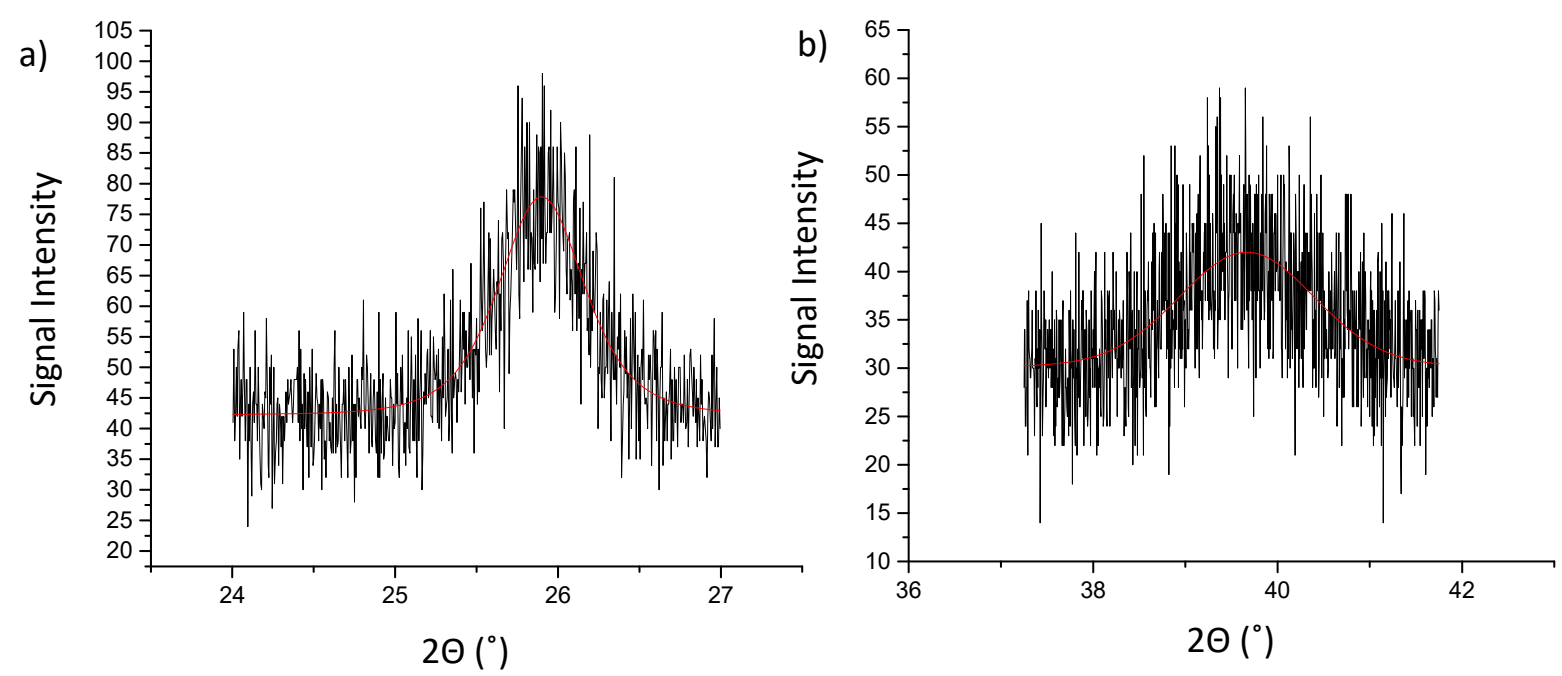

Figure 2: Representative XRD diffractograms of bone samples at a) $26^{\circ}$ peak: indicative of the (002) plane and b) $40^{\circ}$ peak: indicative of the (310) plane. Peaks were assessed the Pearson VII curve fitting function. The full-width half maximum of these peaks was utilized to determine the average dimension of HA crystal length and width respectively. 


\section{Figure 3}

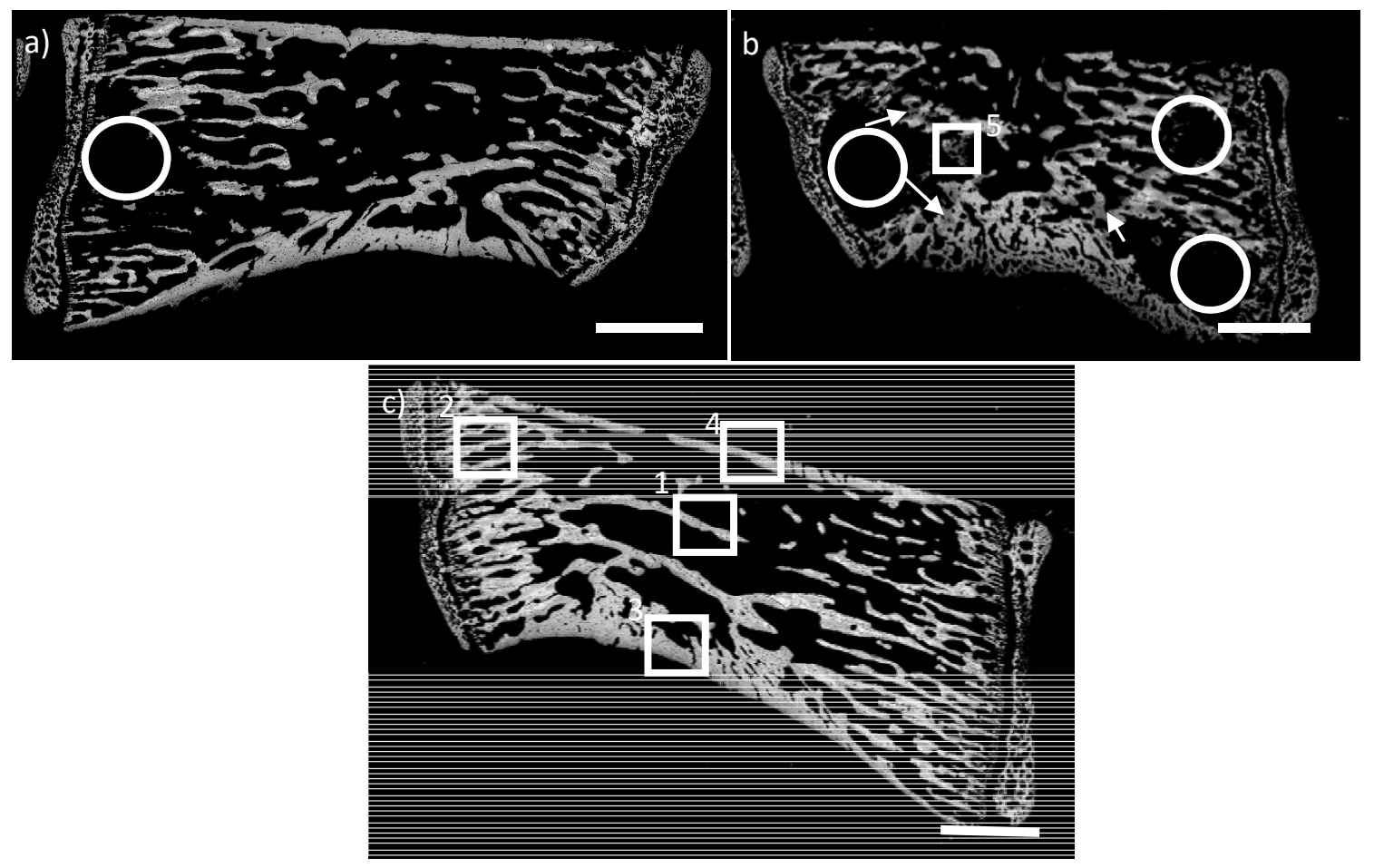

Figure 3: Representative sagittal cross-section BSE images of scanned vertebrae for a) HeLa inoculated b) Ace-1 inoculated and c) healthy control rats. Osteolytic lesion presence is clearly identifiable with voids in trabecular structure (examples highlighted via circle overlay) and pathological osteoblastic new bone growth with a more feathery/lacy/lattice morphology (examples highlighted via white arrows) also observed within Ace-1 inoculated samples. The numbered white square overlays are representative examples of how the locations Centre(1), Edge (2), CortA (3), CortP (4) and New (5) were defined in the anatomy. canlahar-1mm 


\section{Figure 4}
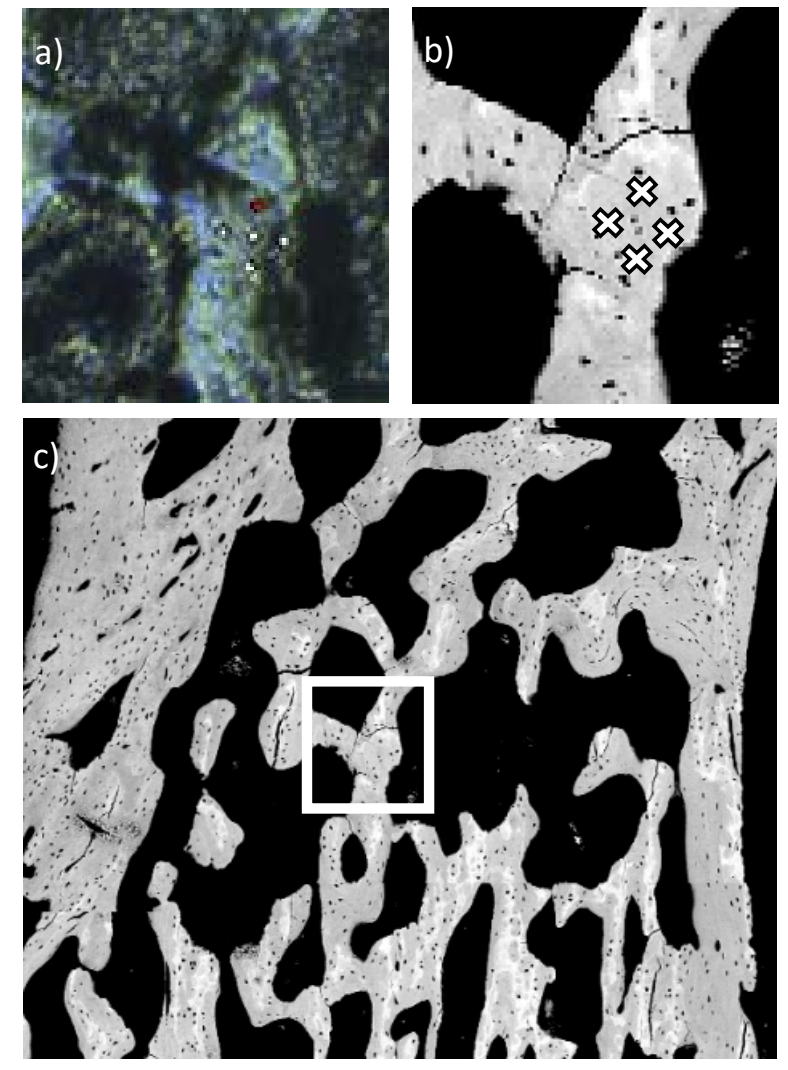

Figure 4: a)LM image of bone surface with GUI created overlay on indent sites (the middle "indent" site is indicative of the reference point rather than an actual indent). b) Identical location obtained in the BSE image. LM image was superimposed in order to determine approximate location of indent sites (highlighted by $x$-marks). $2 \times 2$ pixel greyscale analysis was done at these locations to assess average mineral content by the indent site. c) Square overlay indicative of 100X100 pixel area used in location based BSE analysis. 


\section{Table 1}

\begin{tabular}{|l|l|l|}
\hline Sample Group & Crystal Length $(\AA)$ & Crystal Width $(\AA)$ \\
\hline HeLa $(\mathrm{N}=9)$ & $111.21 \pm 13.34$ & $37.13 \pm 6.68^{*}$ \\
\hline Ace-1 $(\mathrm{N}=7)$ & $106.78 \pm 11.97$ & $42.35 \pm 6.43$ \\
\hline Healthy $(\mathrm{N}=8)$ & $112.42 \pm 16.27$ & $45.35 \pm 5.18$ \\
\hline
\end{tabular}

$* p<0.05$ compared to healthy controls

Table 1: XRD estimated bone crystal length (002) and crystal width (310).

Values expressed as mean \pm STD. 


\section{Figure 5}

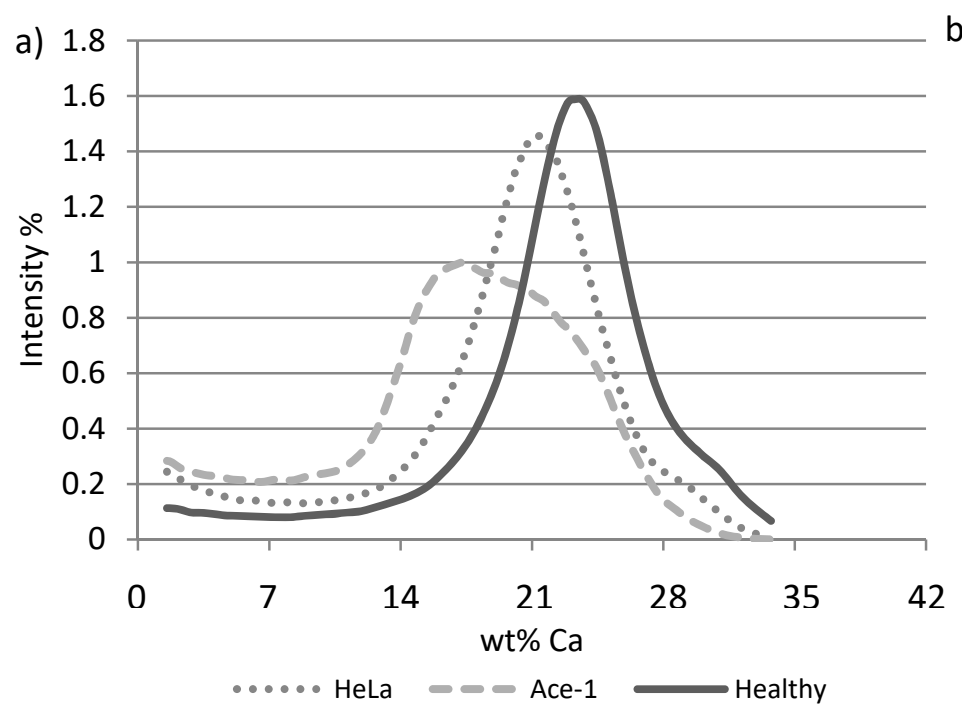

b)

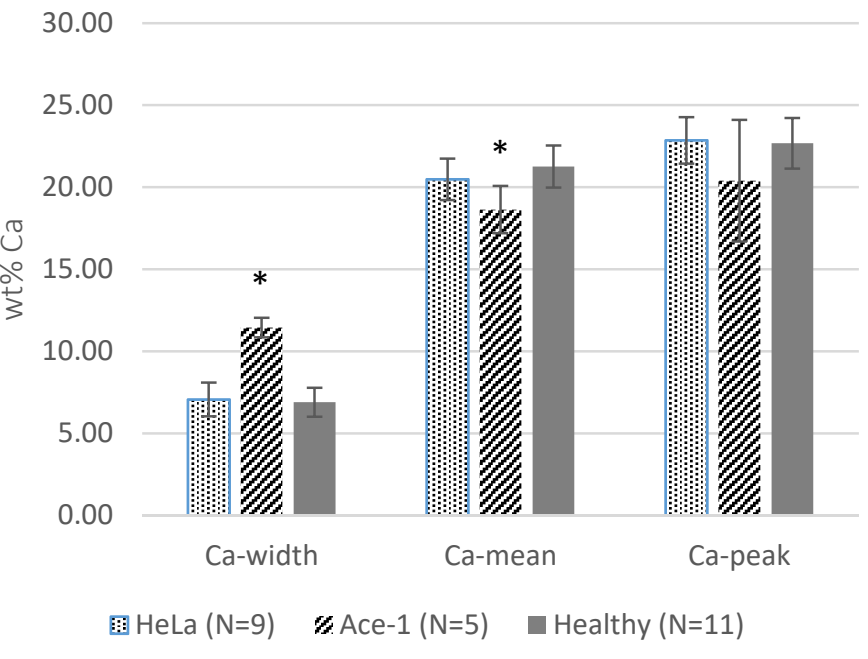

$* p<0.05$ compared to healthy controls

Figure 5: a) Representative examples of wt\% Ca distribution throughout the entire vertebral body cross-section among the different sample groups. As highlighted by $b$ ), the $\mathrm{Ca}_{\text {width }}$ (indicative of mineral crystal distribution heterogeneity) increased and $\mathrm{Ca}_{\text {mean }}$ (indicative of average mineral content) decreased within mixed metastatic bone (from Ace-1 inoculated rats) compared to healthy controls. Error bars represent standard deviation. 


\section{Figure 6}

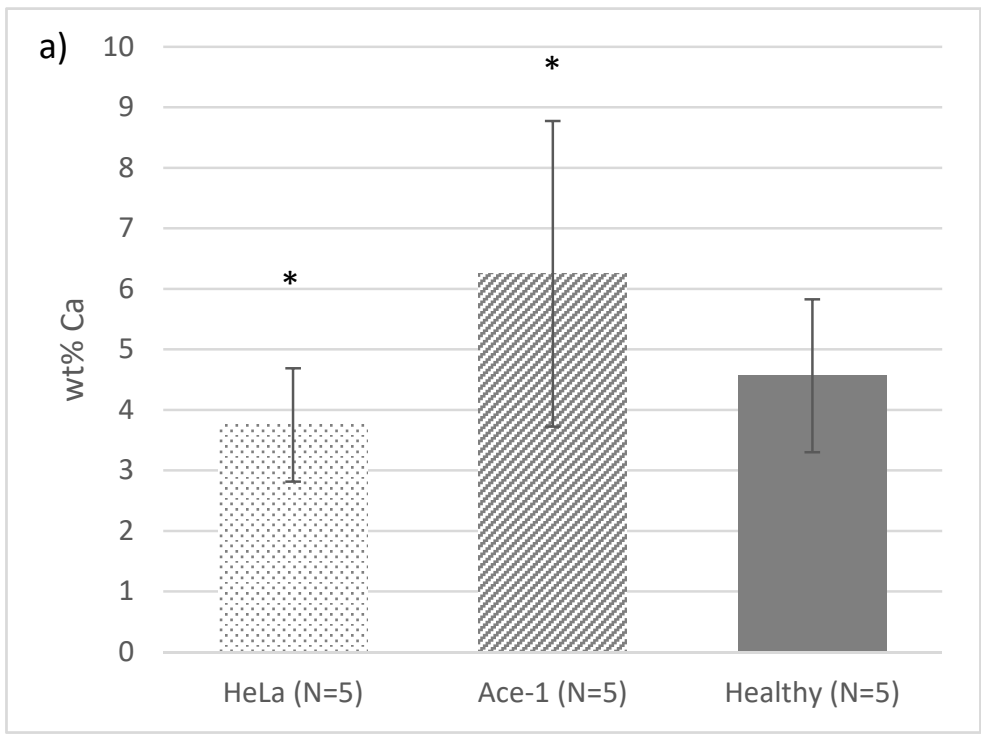

$* p<0.05$ compared to healthy controls b) 12

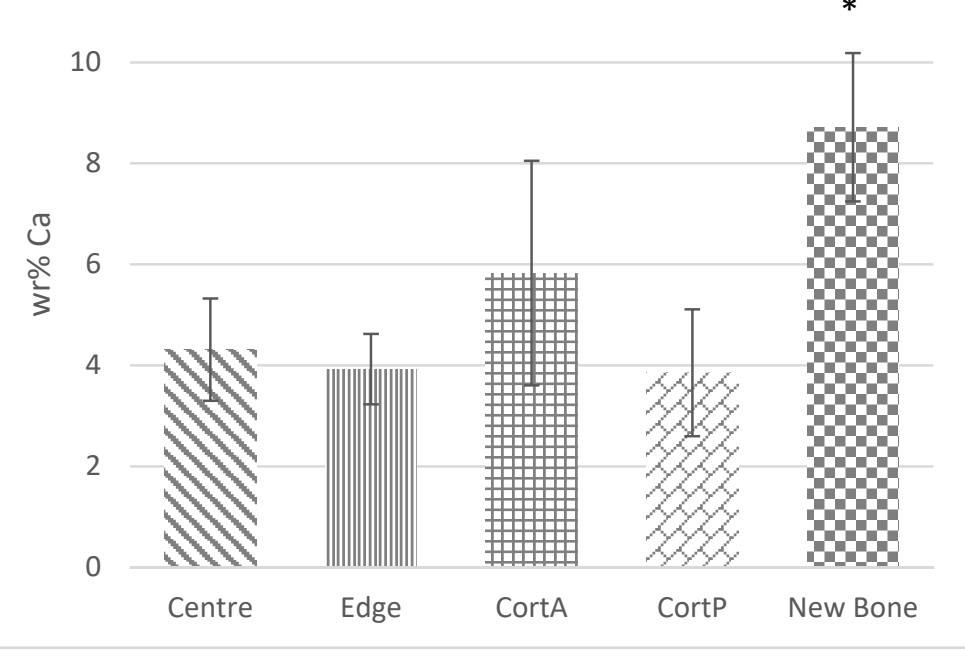

$* p<0.05$ compared to all other locations

Figure 6: Cawidth (mineral distribution heterogeneity) measurements grouped by a) specimen group type and b) location in the vertebral body. Groups with metastatic involvement had significantly modified Cawidth compared to healthy controls. Osteoblastic new bone showed a much wider $\mathrm{Ca}_{\text {width }}$ compared to bone in located elsewhere in the vertebral body. Error bars represent standard deviation. 


\section{Figure 7}

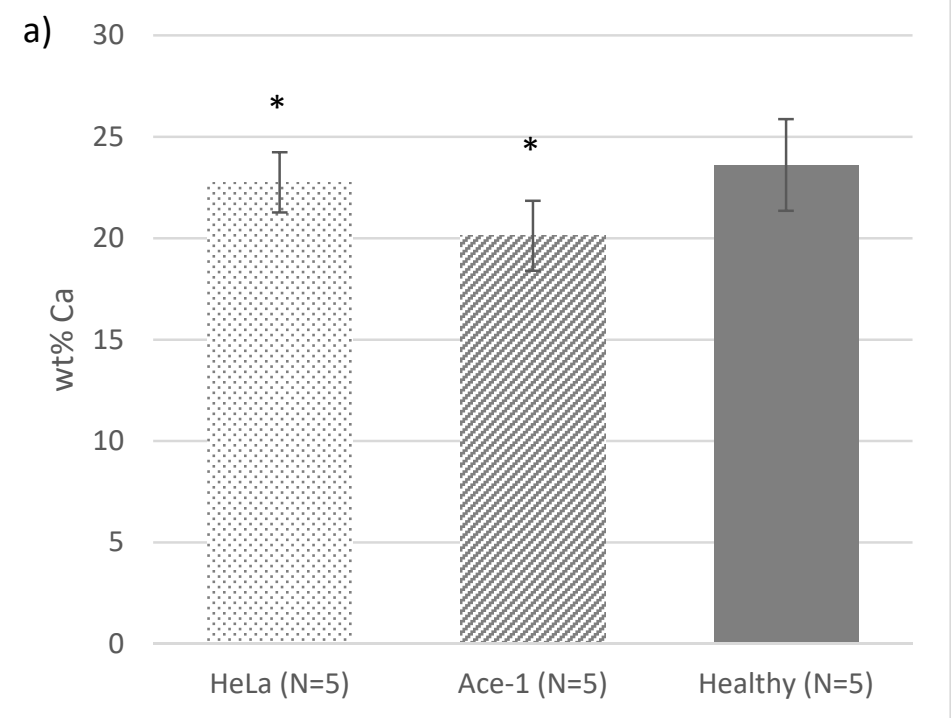

$* p<0.05$ compared to healthy controls b) 30

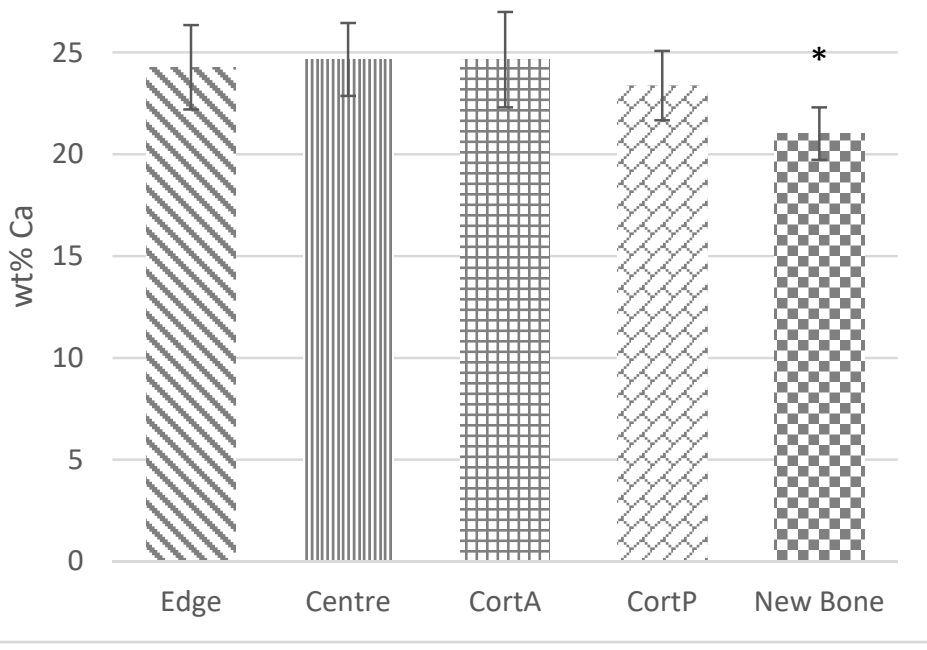

$* p<0.05$ compared to all other locations

Figure 7: Camean (average mineral content) measurements grouped by a) specimen group type and b) location in vertebral body. Groups with metastatic involvement had significantly modified $\mathrm{Ca}_{\text {mean }}$ compared to healthy controls. Osteoblastic new bone showed a much smaller $\mathrm{Ca}_{\text {mean }}$ compared to bone in located elsewhere in the vertebral body. Error bars represent standard deviation. 


\section{Figure 8}

a) 30

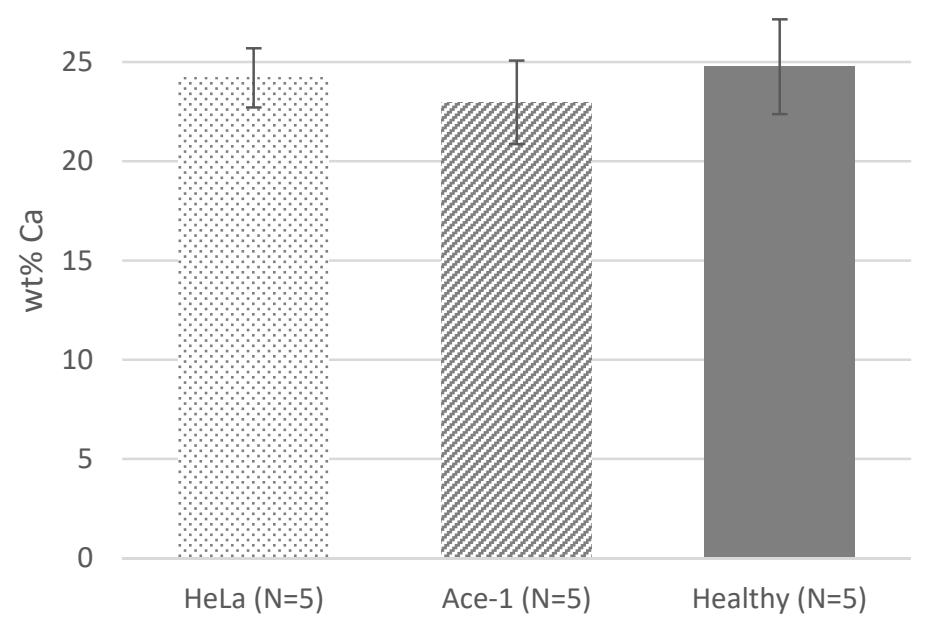

b) 30

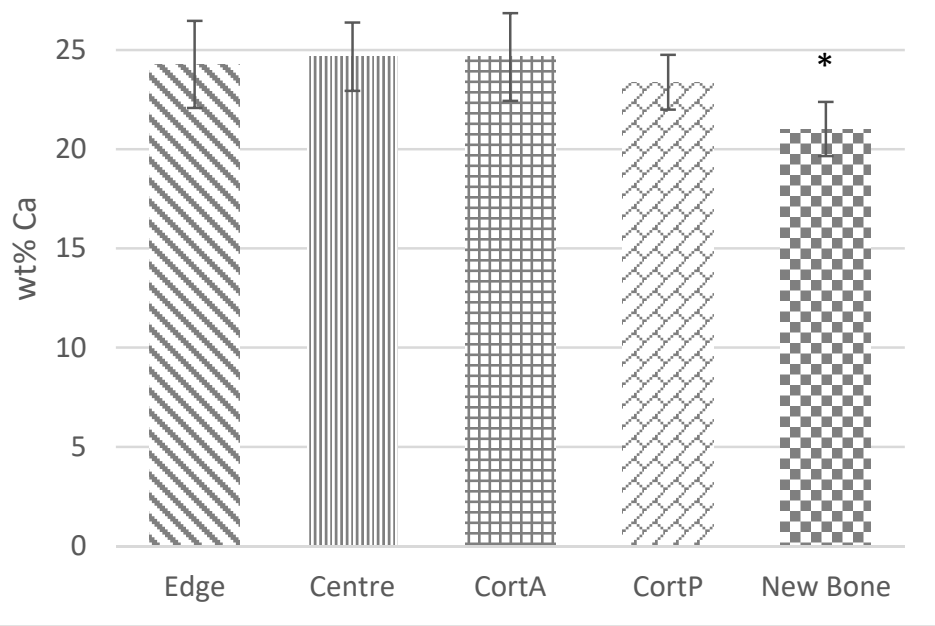

Figure 8: Capeak (peak position) measurements grouped by a) specimen group type and b) location in vertebral body. No significant difference was seen between group types. Location was a significant factor, in particular, pathological osteoblastic bone growth (specific to Ace-1 tumour involvement) having significantly lower Capeak compared to bone in other locations. Error bars represent standard deviation. 


\section{Figure 9}

a)

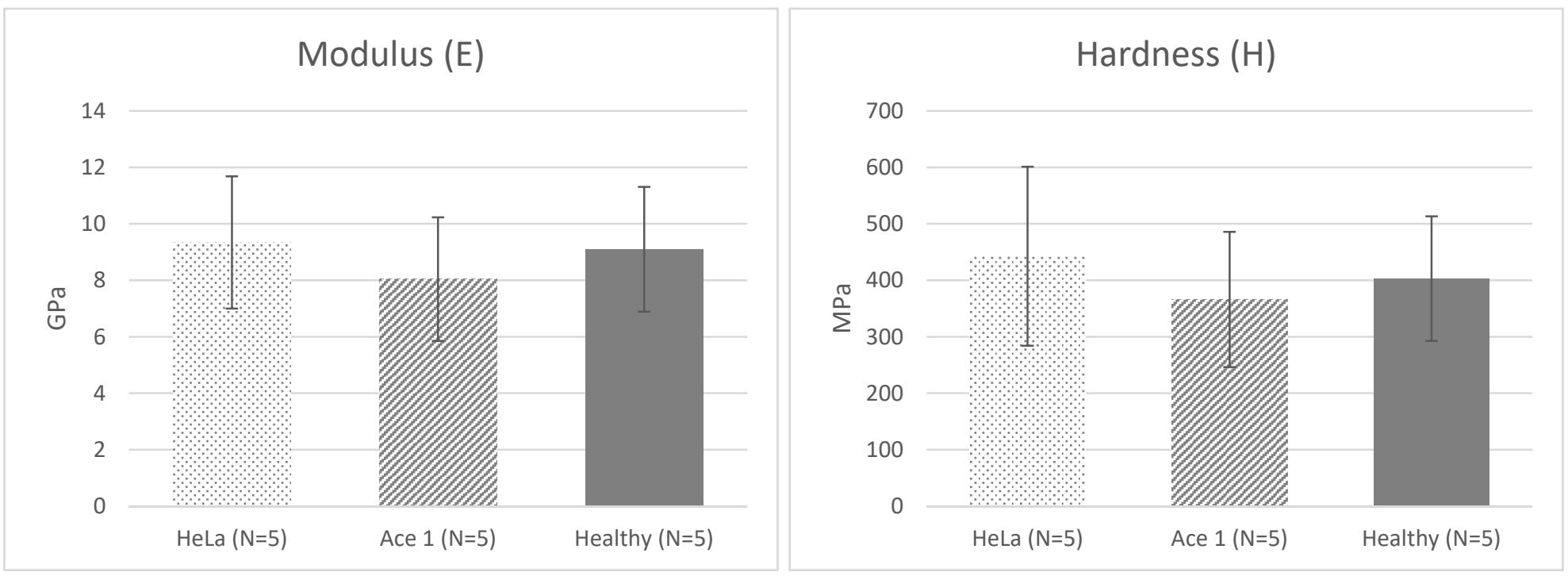

b)
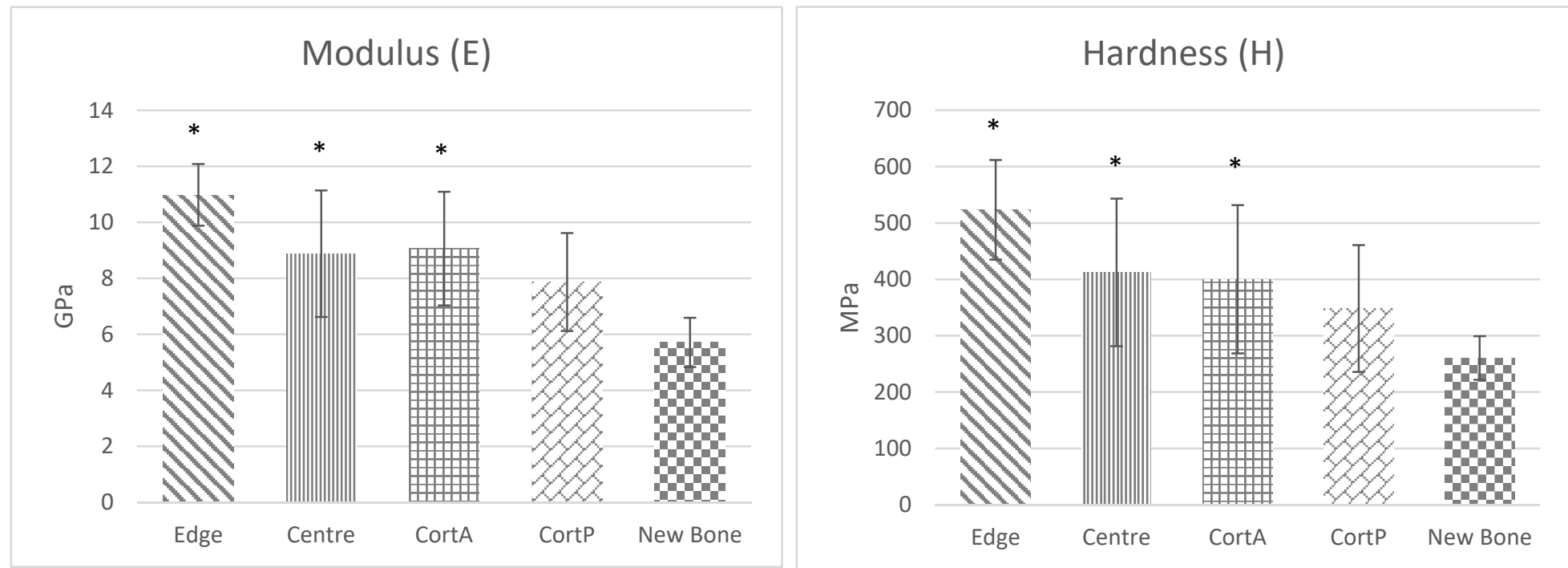

* $p<0.05$ compared to New Bone

Figure 9: Nanoindentation measurements (modulus $(E)$ and hardness $(H)$ ) grouped by a) specimen group type and b) location in vertebral body. No significant difference was seen between group types. Location was a significant factor, in particular, pathological osteoblastic bone growth (specific to Ace-1 tumour involvement) having significantly lower $\mathrm{H}$ and $\mathrm{E}$ compared to bone in other locations. This implies that the significant impact of tumour involvement on material behaviour is focused towards pathological new bone locations which is why type was not seen as a significant factor in general. Error bars represent standard deviation. 
